Header for SpringerLink: Leukemia (JP Dutcher, Section Editor)

\title{
Role of Arsenic Trioxide in Acute Promyelocytic Leukemia
}

\begin{tabular}{|c|c|c|}
\hline Author & Harry J Iland* & John F Seymour \\
\hline Degrees & MBBS(Hons), FRACP, FRCPA, MHGSA & MBBS, FRACP, PhD \\
\hline Affiliations & $\begin{array}{l}\text { 1. Institute of Haematology, Royal } \\
\text { Prince Alfred Hospital, } \\
\text { Missenden Rd, Camperdown, } \\
\text { NSW, Australia } 2050\end{array}$ & $\begin{array}{l}\text { 1. Peter MacCallum Cancer Centre, } \\
7 \text { St Andrews Place, East } \\
\text { Melbourne, VIC, Australia } 3002\end{array}$ \\
\hline & $\begin{array}{l}\text { 2. University of Sydney, Sydney, } \\
\text { NSW, Australia } 2006\end{array}$ & $\begin{array}{l}\text { 2. University of Melbourne, } \\
\text { Melbourne, VIC, Australia } 3010\end{array}$ \\
\hline Phone & +61295158031 & +61396561076 \\
\hline Fax & +61295156698 & +61396561408 \\
\hline Email & harry@email.cs.nsw.gov.au & john.seymour@petermac.org \\
\hline
\end{tabular}

*Corresponding author

\section{Keywords:}

Acute promyelocytic leukemia, arsenic trioxide, all-trans-retinoic acid, PML-RARA, chemotherapy, induction, consolidation, maintenance, toxicity,

QTc prolongation, idarubicin, cytarabine, anthracycline, gemtuzumab ozogamicin. 
Acute promyelocytic leukemia (APL) is a unique subtype of acute myeloid leukemia that is characterized by distinct clinical, morphological, cytogenetic and molecular abnormalities. It is associated with a striking risk of early hemorrhagic death due to disseminated intravascular coagulation and hyperfibrinolysis. The prognosis of APL has improved dramatically following the introduction of all-trans retinoic acid (ATRA) and its combination with anthracycline-based chemotherapy during induction and consolidation. Patients with high-risk APL, defined by a white cell count $>10 \times 10^{9} / \mathrm{L}$ at diagnosis, also appear to benefit from the addition of intermediate- or high-dose cytarabine during consolidation. Arsenic trioxide (ATO) has proved to be even more effective than ATRA as a single agent, and is now routinely used for the treatment of the $20-30 \%$ of patients who manifest disease relapse after initial treatment with ATRA and chemotherapy. ATO has a toxicity profile that differs considerably from that of both ATRA and cytotoxic chemotherapy, and accordingly presents its own specific challenges during treatment. Optimizing a strategy for the incorporation of ATO into initial therapy is currently the focus of several cooperative group trials, with an emphasis on minimizing or even eradicating the use of chemotherapy. ATRA plus ATO without chemotherapy appears to be adequate during induction and consolidation for patients with standard-risk APL, but triple therapy that includes limited anthracycline or gemtuzumab ozogamicin (GO) during induction is required for high-risk APL. Uncertainty still exists regarding the minimum amount of chemotherapy and number of consolidation cycles necessary, the optimal scheduling of ATO, and the potential utility of oral ATO administration. Although prolonged oral maintenance therapy is usually included in most current APL treatment protocols, its value remains controversial, and the superior anti-leukemic efficacy of ATO-based therapy may facilitate its elimination in the future. 
Acute promyelocytic leukemia [1,2] (APL) was first recognized as a specific entity in 1957 [3] on the basis of a preponderance of promyelocytes in the marrow, a propensity for bleeding, and a rapidly fatal course. It accounts for $10-15 \%$ of de novo acute myeloid leukemia (AML) cases, and can also be seen as a form of secondary AML, usually following topoisomerase II inhibitor therapy [4-6]. Unfortunately, the hemorrhagic diathesis of APL is exacerbated by chemotherapy, and an early death rate exceeding $20 \%$ hindered progress until the introduction of all-trans retinoic acid (ATRA) in 1988 [7]. Subsequently, highly significant improvements in outcomes have been achieved following the combination of ATRA with either anthracycline-based chemotherapy or with arsenic trioxide $\left(\mathrm{As}_{2} \mathrm{O}_{3} ; \mathrm{ATO}\right)$.

\section{PATHOGENESIS}

APL originates in a myeloid progenitor cell that, in $99 \%$ of cases, has undergone disruption and rearrangement of $P M L$ and retinoic acid receptor alpha $(R A R A)$ genes [8,9]. This is usually due to a reciprocal translocation between chromosomes 15 and 17 (t(15;17)) [10], but can also occur following complex variant translocations involving chromosomes 15 and 17, or even in cells with an apparently normal karyotype by conventional cytogenetics that have undergone a submicroscopic insertional event [11]. Such cases will still be detected by either FISH probes or molecular assays for the fusion transcript (see below). Transcripts derived from PML-RARA fusion genes encode an abnormal retinoic acid receptor (PML-RARA) that disrupts myeloid differentiation programs normally mediated by RARA, and impairs the tumor suppressor activity and a variety of nuclear body functions normally mediated by PML. In the $1 \%$ of patients who lack PML-RARA rearrangements, alternative partners are fused with $R A R A$, most 
commonly PLZF [12], and rarely NPM1 [13], NUMA [14], STAT5b [15], PRKAR1A [16], FIP1L1 [17], or BCOR [18]. Although published clinical experience with these variant forms of APL is limited, they appear to exhibit differential responsiveness to ATRA and ATO [19].

Disruption of normal myeloid differentiation by chimeric PML-RARA proteins is associated with maturation arrest at the promyelocyte stage. Murine models of APL indicate PML-RARA is necessary, but not sufficient, for leukemogenesis and additional genetic abnormalities are required to provide a proliferative signal $[20,21]$. In $40-50 \%$ of patients with APL that signal appears to be provided by constitutive activation of $F L T 3$ [22,23] resulting from either an internal tandem duplication in the juxta-membrane or kinase-I domains, or point mutation in the kinase-II domain. The origin of the putative proliferative signal in the remainder has not yet been identified.

\section{CLINICAL FEATURES}

The median age at diagnosis is approximately 45 years, and APL affects both sexes equally [24]. In the US, the age-adjusted annual incidence is 0.23 per 100,000 population. For unexplained reasons, the incidence of APL is substantially higher in Latinos [25], and the body mass index of patients with APL is significantly greater than that of patients with other subtypes of AML [26]. Bleeding dominates the initial presentation, and initiation of ATRA combined with aggressive platelet and plasma support to correct the hemostatic defects should be undertaken as soon as the diagnosis is suspected. Pancytopenia is usually present, with a median white cell count (WCC) around $2.5 \times 10^{9} / \mathrm{L}$. In approximately $80 \%$ of patients the promyelocytes are hypergranular, often with numerous Auer rods (classical APL), and this subtype was designated M3 in the French-American-British 
classification of AML. The remaining patients have the variant microgranular form (M3v), with bilobed nuclei and few or no Auer rods. The hemostatic defect that is almost inevitably present at diagnosis is multifactorial [27•], with contributions from primary fibrinolysis and fibrinogenolysis, procoagulant activation with disseminated intravascular coagulation (DIC), secondary fibrinolysis, and endothelial/monocyte perturbation by inflammatory cytokines. In addition, thrombocytopenia may be severe due to both DIC and leukemia-associated marrow failure.

PML-RARA fusion genes can be detected in bone marrow preparations by fluorescence in situ hybridization with PML-RARA fusion or RARA breakapart probes, and PML-RARA transcripts are readily identified in reverse transcriptase polymerase chain reaction (RT-PCR) assays. The PML protein normally resides in large macromolecular intra-nuclear structures known as nuclear bodies, and these are disrupted in APL [28]; this phenomenon can be exploited as a rapid diagnostic test by the use of immuno-fluorescence with anti-PML antibodies [29].

Features that have been associated with an inferior prognosis include a higher WCC, lower platelet count, older age, FLT3 mutation, CD56 expression, and longer time to achieve remission. The Sanz risk classification [30], based on cut-points for WCC (10 x $\left.10^{9} / \mathrm{L}\right)$ and platelet count (40 $\mathrm{x}$ $\left.10^{9} / \mathrm{L}\right)$ is widely used to stratify patients.

\section{CURRENT TREATMENT OPTIONS}

Prior to the use of ATRA, APL was regarded as the AML subtype with the poorest prognosis, primarily due to early deaths as a result of intracerebral or intrapulmonary hemorrhage. Such bleeding was aggravated when cytotoxic chemotherapy was commenced. Since ATRA relieves the 
differentiation block and rapidly reverses the hemostatic abnormalities, the risk of early hemorrhagic death is now $<10 \%$, provided optimal hemostatic support is also delivered. Notably, the reduction in early deaths has been striking for patients treated in the clinical trial setting, but in population-based studies, the early death rate remains disturbingly high [24]. Unfortunately ATRA is also associated with a potentially fatal capillaryleak syndrome, originally termed "retinoic acid syndrome" [31], and now known as APL "differentiation syndrome" (DS). DS is characterized by fever, pulmonary infiltrates and hypoxia, pleural and pericardial effusions, and weight gain.

Following the initial report from Shanghai of the efficacy of ATRA [7], in which all 24 patients treated achieved complete remission (CR), the necessity for its inclusion as part of initial therapy was unequivocally established in the European APL91 trial [32] that compared ATRA plus chemotherapy (daunorubicin and cytarabine) with chemotherapy alone. The study was terminated when an interim analysis demonstrated that the ATRAcontaining arm was associated with superior event-free survival (79 vs 50\%) and a significantly lower relapse rate (19 vs $40 \%)$ at 12 months. In the group's subsequent trial (APL93), treatment with concurrent ATRA and chemotherapy was associated with significantly fewer relapses than sequential ATRA and chemotherapy [33].

Precisely which chemotherapeutic agents are most active in APL has long been controversial. Retrospective multivariate analysis of data from Southwest Oncology Group AML trials [34] suggested that outcomes were improved with increased cumulative doses of daunorubicin, whereas cytarabine dose and inclusion of other agents were not significantly associated with outcome. Data from the GIMEMA group also indicated that 
another anthracycline, idarubicin, was particularly active in APL [35]. They then combined ATRA with idarubicin in the AIDA 0493 protocol [36], and this combination has proven highly effective, especially when followed by consolidation that also utilizes anthracycline-based chemotherapy [37].

Although early studies suggested cytarabine was of no benefit in APL, recent studies $[38,39 \bullet, 40]$ which utilize intermediate- or high-dose cytarabine during consolidation have demonstrated improved outcomes, particularly for patients with high-risk disease. However, death in remission due to chemotherapy-related toxicity remains an area of concern with such an approach. While ATO is regarded as the treatment of choice for patients whose disease relapses after ATRA and chemotherapy (discussed below), its inclusion in the initial treatment of APL has occurred more slowly. A small randomized study [41] showed that time to CR and the depth of molecular response with the combination of ATRA plus ATO during induction was superior to either agent used alone, and four more recent studies from the MD Anderson Cancer Center [42•], the US Intergroup [43••], the Australasian Leukaemia and Lymphoma Group (ALLG) [44••], and an Italian-German cooperative study [45••] have all confirmed the benefit of incorporating ATO into induction and/or consolidation.

\section{TREATMENT}

Treatment with arsenic trioxide

\section{HISTORICAL ASPECTS}


- The use of medicinal arsenic in traditional Chinese medicine dates back more than 2000 years, as documented in the Shennong Materia Medica compiled during the Han dynasty (200BC). Its historical applications in both traditional Chinese and Western medicine have been eloquently reviewed [46]. The first treatment of a patient with APL using a crude ATO preparation (Ailing No. 1), was in 1973, and 73 cases were published in 1981 [47], several years before the benefits of ATRA were appreciated. A further 32 cases were reported in the Chinese literature in 1992 [48], with 66\% achieving CR. Investigators from Shanghai and Harbin subsequently showed that ATO could induce both differentiation and apoptosis of APL cells in a dose-dependent manner [49], and it is now recognized that ATO has potent and relatively selective activity against APL-initiating cells via its ability to induce PML-RARA fusion protein degradation [50,51].

\section{TREATMENT OF RELAPSED APL WITH ATO}

- Despite its long history in traditional Chinese medicine, it was not until the latter part of the $18^{\text {th }}$ century that therapeutic arsenic appeared in the Western medical literature. It was used for the treatment of agues, malaria, syphilis, skin conditions, and parasitic infestations, and was particularly popular in veterinary medicine. In 1865, Lissauer used potassium arsenite (Fowler's solution) to treat a woman with chronic myeloid leukemia (CML), and in 1931 Forkner and Scott reported substantial improvements in blood counts and reduction of splenomegaly in 9 of 10 patients with CML [52]. Another 66 years passed before the benefits of ATO for the treatment of relapsed APL were described in Western literature [53]. Fourteen of 15 patients with APL that had relapsed after ATRA and chemotherapy achieved CR with intravenous (IV) 
ATO, either alone or with ATRA or low dose chemotherapy. ATO was rapidly eliminated from plasma, but reversibly accumulated in hair and nails, where its concentration declined after treatment cessation.

- This remarkable success with ATO was replicated in a pilot study in New York [54], in which 11 of 12 patients with heavily pre-treated relapsed APL achieved CR, including 8 who achieved molecular remission. Evidence of both differentiation (progressive reduction in CD33 and increase in CD11b expression) and apoptosis (caspase activation) were demonstrated, consistent with the previously reported in vitro data.

- This pilot study was followed by a US Multicenter study [55] of ATO in 40 patients with relapsed APL who were treated for up to 60 days, followed by one consolidation cycle of up to 35 days, with further maintenance cycles permitted. The CR rate was $85 \%$, and molecular CR was attained in $86 \%$ following consolidation. At 18 months, overall survival (OS) and relapse-free survival (RFS) were 66 and $56 \%$ respectively, although patients were not censored at the time of subsequent transplants ( 8 allogeneic and 3 autologous). Toxicities included gastrointestinal effects (nausea, vomiting and diarrhea), hyperleukocytosis and APL DS, QTc prolongation $>500$ msec, peripheral neuropathy, and hepatic dysfunction. Despite the small sample size, these data secured regulatory approval for ATO in the treatment of relapsed/refractory APL after ATRA/anthracycline in the US, after retinoid/chemotherapy in Europe, and for the treatment of relapsed APL in Australia. 
- Other, mostly supportive, data from nearly 200 patients for the use of ATO in relapsed APL have been published from many centers, including reports from Shanghai $(n=47)$ [56], Melbourne $(n=2)$ [57], Hong Kong ( $n=29)[58,59]$, Florence $(n=7)[60]$, Paris $(n=20)[61]$, Hamamatsu $(n=34)$ [62], Houston $(n=20)[63,64]$, Rome $(n=11)$ [65], and multiple French institutions $(n=25)$ [66]. The dose of ATO used was either 10mg/day or $0.15 \mathrm{mg} / \mathrm{kg} /$ day. The Shanghai group also described apparently comparable results in 20 patients treated with half-dose ATO (0.08mg/kg/day), and observed a lower incidence of facial edema, gastrointestinal and cardiac toxicity [67].

- The duration of ATO therapy, the addition of other agents such as ATRA and chemotherapy or GO, and the contribution of subsequent autologous or allogeneic stem-cell transplantation to the favorable outcomes achieved with ATO in the relapse setting have all been highly variable. Of particular interest is a study from Vellore [68•] in patients with relapsed APL who underwent salvage with an ATO-based regimen. Thirty-three of 37 patients achieved molecular remission, and received consolidation with further ATO \pm ATRA, or an autologous stem-cell transplant after busulfan/cyclophosphamide conditioning. Although not a randomized study, a significantly lower EFS (34.5\%) was observed with ATO treatment compared with autologous transplantation (83.3\%; $p=0.001$ ). These data contrast with an earlier report from Hong Kong [59] suggesting better OS when patients with relapsed APL underwent salvage with ATO and idarubicin, compared with ATRA/chemotherapy \pm allogeneic bone marrow transplantation, despite a high relapse rate in the ATO cohort (38\%). Accordingly, apart from the use of ATO as the cornerstone for the treatment of relapsed APL after ATRA and chemotherapy, there is no clear consensus on optimal management after achievement of a second remission [69]. 


\section{ATO AS INITIAL THERAPY FOR APL}

- The impressive results obtained with ATO in the treatment of relapsed APL clearly suggested a potential role in initial therapy, either alone or in combination with other agents. However, enthusiasm was muted when 7 cases of hepatic toxicity, including 2 fatalities, were observed among 11 patients with newly diagnosed APL treated with ATO [56]. The authors argued that ATO should therefore not be used as initial therapy, but a subsequent larger study from Shanghai provided more reassuring efficacy and toxicity data. Shen et al compared single agent ATRA, single agent ATO, and combined ATRA/ATO in a randomized study of 61 patients. The CR rates were similar in all 3 arms (90-95\%), but statistically significant differences in the median time to CR were observed (ATRA 40.5, ATO 31, ATRA/ATO 25.5 days). These results were supplemented by quantitative PML-RARA RT-PCR as a measure of residual disease, with the lowest levels observed in the combination group following both induction and consolidation, reinforcing the impression that ATRA and ATO act synergistically. Even more importantly, no relapses were observed in the group that received combination therapy, whereas 2 relapses were seen with ATO, and 5 with ATRA.

- The median follow-up was only 18 months at initial publication, but updated results [70] with combination ATRA/ATO in 85 patients and a median follow-up of 5.8 years described a $94 \%$ CR rate, with 5 -year probabilities of RFS and OS an impressive $94.8 \%$ and $91.7 \%$, respectively. 
Although ATRA and ATO were used for remission induction and maintenance, it is noteworthy that remissions were extensively consolidated with multiple cycles of chemotherapy, incorporating daunorubicin, conventional- and intermediate-dose cytarabine, and homoharringtonine (omacetaxine mepesuccinate).

- Similar data were also reported from Changsha [71]; time to CR was shorter with an ATRA/ATO combination during induction compared with ATRA alone. Furthermore, patients who received 10 cycles of post-remission combination chemotherapy had a $3-y e a r$ RFS of $72 \%$, and this was improved to $93 \%$ by replacing four of the chemotherapy cycles with ATO.

- Motivated by a desire to eliminate chemotherapy from the initial management of APL, investigators from the MD Anderson Cancer Center treated 44 patients with ATRA and ATO for induction and consolidation [72]. Nineteen patients with high-risk disease (WCC $\left.\geq 10 \times 10^{9} / \mathrm{L}\right)$ were also given GO on day 1. CR was achieved in $89 \%$ ( $96 \%$ in low-risk, $79 \%$ in high-risk); 3 patients with high-risk disease relapsed, whereas no relapses were observed in the 25 patients with low-risk disease. A subsequent report [42•] from this group included 65 patients treated with the original protocol, and a second cohort of 17 patients where low-risk disease was also treated with GO if the WCC rose above $30 \times 10^{9} / \mathrm{L}$ during induction. The 3 -year OS was $85 \%$, and DFS $81 \%$. 
- Whilst ATO manufactured under patent protection is relatively expensive, its low production cost in other locations has encouraged its use as an alternative to ATRA/chemotherapy in induction and consolidation of previously untreated patients. Studies from Vellore [73] and Tehran [74] showed that induction regimens based almost entirely on single agent ATO achieved relatively high CR rates (approximately $86 \%$ in both locations); hydroxyurea was used for patients with elevated WCC in both studies, and limited anthracycline was also given to a minority of patients in the Vellore study. Furthermore, ATO monotherapy was also used for consolidation/maintenance in both studies, although the scheduling was quite different. Mature survival data from both studies $\left[77^{\bullet}, 76 \bullet\right]$ have recently been reported. At 5 years, the Vellore results for DFS (80\%) and OS (74\%) appear superior to those from Tehran (67 and 64\%, respectively), and this difference most likely reflects differences in overall duration of ATO exposure.

- Whereas most experience with ATO in the initial treatment of APL is derived from single-arm studies, the North American Leukemia Intergroup conducted a randomized study (C9710 [43••]) to test the hypothesis that the early addition of ATO to post-remission therapy would improve EFS in this setting. After induction with ATRA, daunorubicin and cytarabine, patients in CR received consolidation with ATRA/daunorubicin. Patients randomized to the ATO arm also received two cycles of ATO (5 days/week for 5 weeks). Both EFS and DFS were significantly improved in the ATO arm, although this study has been criticized because the control arm performed relatively poorly. For example, 3-year DFS was $90 \%$ in the ATO arm and only $70 \%$ in the control arm $(p<0.0001)$, whereas another non-ATO protocol that was carried out over a similar time frame (PETHEMA LPA99 [40]) achieved an 87\% 3-year DFS. Nevertheless, the C9710 study demonstrated the 
multi-centre feasibility of delivery, and effectiveness, of ATO in consolidation therapy. Post-remission ATO has also been used as a substitute for a second cycle of ATRA/chemotherapy consolidation in a single-arm North American study [77], achieving an 89\% 3-year DFS that was comparable to the ATO-arm in C9710.

- It is essential to remember that differentiation block at the promyelocyte stage of myelopoiesis, which effectively defines APL, is complicated by two intersecting biological phenomena. On the one hand, there is a severe coagulopathy, but strategies that control the coagulopathy by releasing the differentiation block have the potential to cause a life-threatening DS. Therefore the attraction of an ATRA plus chemotherapy combination, typified by the GIMEMA group's AIDA protocols [36, 39•], is that ATRA corrects the coagulopathy that is aggravated by idarubicin, and idarubicin protects against ATRA-induced DS. In contrast, despite the theoretical appeal of an ATRA and ATO combination (the two most potent agents in APL), their synergism creates a dilemma since both can also cause the APL DS. This is of particular concern for patients with high-risk disease (WCC $\left.>10 \times 10^{9} / \mathrm{L}\right)$, who are at greatest risk of hyperleukocytosis which usually accompanies DS. To address this concern, the ALLG incorporated ATRA, ATO and idarubicin during induction in their APML4 protocol [44••], aiming to maximize anti-leukemic efficacy whilst simultaneously controlling coagulopathy and DS. Consolidation involved two cycles of ATRA and ATO, without any further anthracycline or cytarabine. The results of an interim analysis have been published, and demonstrate excellent results with an early death rate of 3.2\%, CR 95\%, 2-year freedom from relapse and DFS rates of 97.5\%, and 93.2\% 2-year OS. These results were compared with a 
previous non-ATO ALLG protocol (APML3) that used ATRA and idarubicin for both induction and consolidation [78]. APML4 was associated with significantly greater freedom from relapse and failure-free survival.

- All patients in the APML4 study were treated identically, regardless of Sanz risk category, and WCC was not an adverse risk factor for early death, relapse (Figure 1) or OS, suggesting that some anthracycline is beneficial even when an ATRA/ATO combination is used. However, this may only be necessary for patients with high-risk disease, since a randomized study [45••] in patients with low-risk disease $\left(\right.$ WCC $\leq 10 \times 10^{9} /$ L) presented at the 2012 American Society of Hematology meeting showed that ATRA/ATO for induction and consolidation was non-inferior, and possibly superior, to an ATRA/chemotherapy (AIDA) protocol.

- Table 1 summarizes the regimens and outcome data that have been reported when ATO has been included as part of induction or postremission therapy for previously untreated patients with APL.

\section{ATO TOXICITY}

- The short-term toxicity profile of therapeutic ATO has been well documented in the studies described above, and comprehensively reviewed by investigators from Hong Kong [79] (Table 2). In general, toxicity is ameliorated by dose reduction, or by temporary interruption. Active surveillance for QTc prolongation with twice weekly electrocardiographs and strict attention to electrolyte levels (especially $\mathrm{K}^{+}$and $\mathrm{Mg}^{2+}$ ) is 
essential to prevent the development of significant and potentially fatal ventricular arrhythmias, at least with intravenous ATO. Scheduling plays an important part in the frequency of ATO side-effects, since the first cycle of consolidation in the APML4 trial, when ATO was administered daily, was associated with considerably more toxicity than the second cycle, when ATO was administered on 5 days/week $[44 \bullet \bullet]$. Whereas chronic environmental arsenic exposure is associated with an increased risk of malignancy, second malignancies attributable to therapeutic ATO for APL have not been convincingly demonstrated.

\section{ORAL ATO}

- Orally administered ATO offers several potential advantages over IV administration, primarily related to logistic issues and lower hospital resource utilization [80]. Oral ATO is associated with lower peak blood levels than after IV administration, but overall arsenic exposure, as estimated by area-under-the-curve, appears comparable [81]. It has been claimed that oral ATO does not cause ventricular arrhythmias because of the lower peak levels, yet a study of oral ATO in relapsed APL found 3 of 16 patients (19\%) experienced QTc prolongation beyond $500 \mathrm{msec}$ [82], whereas a much larger study with IV ATO documented QTc prolongation in 17 of 120 patients $(14 \%)$ during induction [44••]. The efficacy of oral ATO has primarily been demonstrated in the maintenance setting after first remission $[80,83 \bullet]$, and for the treatment of relapsed adult [82] and pediatric [84] APL, and its use has been enthusiastically promoted by investigators from Hong Kong, where an oral formulation has been developed and registered for the treatment of APL. 


\section{ALTERNATIVE ARSENIC FORMULATIONS}

- While the vast majority of publications related to arsenic therapy in APL have involved treatment with ATO, other arsenic derivatives have been examined. Realgar, an ore composed primarily of tetra-arsenic tetra-sulfide $\left(\mathrm{As}_{4} \mathrm{~S}_{4}\right)$, also has a long history in traditional Chinese medicine. $\mathrm{As}_{4} \mathrm{~S}_{4}$ has been shown in a small study to be effective in previously untreated and relapsed APL, and for long term maintenance therapy [85]. It is administered orally, and its toxicity profile is similar to that of ATO. Notably, it can also produce QTc prolongation, and hyperleukocytosis, but usually without other features of DS. Phase III data [86•] currently available in abstract form from the Chinese APL Cooperative Group demonstrate that an oral arsenic-containing Realgar-Indigo naturalis formula and intravenous ATO are associated with comparably high CR rates and long term survival. Other arsenic derivatives whose activity in APL has not yet been well established include liposomal ATO [87], and several orally bioavailable organic arsenic derivatives (e.g. darinaparsin [88] and melarsoprol [89]) which appear to have significant anti-tumor activity. However the likelihood that these agents will be developed for the treatment of APL is remote, as unlike ATO their cytotoxic effects are not mediated by PML-RARA degradation.

Disclosure: H.J. Iland: Provided expert testimony to Phebra, received payment for development of educational presentations from Novartis and Elsevier, and had travel/accommodations expenses covered or reimbursed from Roche; J.F Seymour: Consultancy for Phebra. 


\section{References and Recommended Reading}

Papers of particular interest, published recently, have been highlighted as:

- Of importance

-. Of major importance

1. Swerdlow S, Campo E, Harris N et al: WHO Classification of Tumours of Haematopoietic and Lymphoid Tissue: The International Agency for Research on Cancer; Lyon, 2008.

2. Wang Z-Y, Chen Z: Acute promyelocytic leukemia: from highly fatal to highly curable. Blood 2008, 111:2505-2515.

3. Hillestad LK: Acute promyelocytic leukemia. Acta Medica Scandinavica 1957, 159:189-194.

4. Detourmignies L: Therapy-related acute promyelocytic leukemia: a report on 16 cases. J Clin Oncol 1992, 10:1430-1435.

5. Mistry AR, Felix CA, Whitmarsh RJ et al: DNA topoisomerase II in therapy-related acute promyelocytic leukemia. N Engl J Med 2005, 352:15291538.

6. Hasan SK, Mays AN, Ottone T et al: Molecular analysis of $\mathrm{t}(15 ; 17)$ genomic breakpoints in secondary acute promyelocytic leukemia arising after treatment of multiple sclerosis. Blood 2008, 112:3383-3390.

7. Huang ME, Ye YC, Chen SR et al: Use of all-trans retinoic acid in the treatment of acute promyelocytic leukemia. Blood 1988, 72:567-572.

8. de The $\mathrm{H}$, Chomienne $\mathrm{C}$, Lanotte $\mathrm{M}$ et al: The $\mathrm{t}(15 ; 17)$ translocation of acute promyelocytic leukaemia fuses the retinoic acid receptor alpha gene to a novel transcribed locus. Nature 1990, 347:558-561.

9. Kakizuka A, Miller WH, Jr., Umesono K et al: Chromosomal translocation t(15;17) in human acute promyelocytic leukemia fuses RAR alpha with a novel putative transcription factor, PML. Cell 1991, 66:663-674.

10. Larson RA, Kondo K, Vardiman JW et al: Evidence for a 15;17 translocation in every patient with acute promyelocytic leukemia. Am J Med 1984, 76:827-841.

11. Grimwade D, Biondi A, Mozziconacci MJ et al: Characterization of acute promyelocytic leukemia cases lacking the classic $t(15 ; 17)$ : results of the European Working Party. Groupe Francais de Cytogenetique Hematologique, Groupe de Francais d'Hematologie Cellulaire, UK Cancer 
Cytogenetics Group and BIOMED 1 European Community-Concerted Action "Molecular Cytogenetic Diagnosis in Haematological Malignancies". Blood 2000, 96:1297-1308.

12. Chen Z, Brand NJ, Chen A et al: Fusion between a novel Kruppel-like zinc finger gene and the retinoic acid receptor-alpha locus due to a variant $\mathrm{t}(11 ; 17)$ translocation associated with acute promyelocytic leukaemia. EMBO J 1993, 12:1161-1167.

13. Redner R, Rush E, Faas $\mathrm{S}$ et al: The $\mathrm{t}(5 ; 17)$ variant of acute promyelocytic leukemia expresses a nucleophosmin-retinoic acid receptor fusion. Blood 1996, 87:882-886.

14. Wells RA, Catzavelos C, Kamel-Reid S: Fusion of retinoic acid receptor alpha to NuMA, the nuclear mitotic apparatus protein, by a variant translocation in acute promyelocytic leukaemia. Nat Genet 1997, 17:109-113.

15. Arnould C, Philippe C, Bourdon V et al: The signal transducer and activator of transcription STAT5b gene is a new partner of retinoic acid receptor alpha in acute promyelocytic-like leukaemia. Hum Mol Genet 1999, 8:1741-1749.

16. Catalano A, Dawson MA, Somana $K$ et al: The PRKAR1A gene is fused to RARA in a new variant acute promyelocytic leukemia. Blood 2007, 110:4073-4076.

17. Kondo T, Mori A, Darmanin S et al: The seventh pathogenic fusion gene FIP1L1-RARA was isolated from a t(4;17)-positive acute promyelocytic leukemia. Haematologica 2008, 93:1414-1416.

18. Yamamoto $Y$, Tsuzuki S, Tsuzuki M et al: BCOR as a novel fusion partner of retinoic acid receptor alpha in a $t(X ; 17)(p 11 ; q 12)$ variant of acute promyelocytic leukemia. Blood 2010, 116:4274-4283.

19. Mistry AR, Pedersen EW, Solomon E, Grimwade D: The molecular pathogenesis of acute promyelocytic leukaemia: implications for the clinical management of the disease. Blood Rev 2003, 17:71-97.

20. Brown D, Kogan S, Lagasse E et al: A PMLRARalpha transgene initiates murine acute promyelocytic leukemia. Proc Natl Acad Sci U S A 1997, 94:2551-2556.

21. Kelly LM, Kutok JL, Williams IR et al: PML/RARalpha and FLT3-ITD induce an APL-like disease in a mouse model. Proc Natl Acad Sci U S A 2002, 99:8283-8288. 
22. Kottaridis PD, Gale RE, Frew ME et al: The presence of a FLT3 internal tandem duplication in patients with acute myeloid leukemia (AML) adds important prognostic information to cytogenetic risk group and response to the first cycle of chemotherapy: analysis of 854 patients from the United Kingdom Medical Research Council AML 10 and 12 trials. Blood 2001, 98:1752-1759.

23. Beitinjaneh A, Jang S, Roukoz H, Majhail NS: Prognostic significance of FLT3 internal tandem duplication and tyrosine kinase domain mutations in acute promyelocytic leukemia: a systematic review. Leuk Res 2010, 34:831-836.

24. Park JH, Qiao B, Panageas KS et al: Early death rate in acute promyelocytic leukemia remains high despite all-trans retinoic acid. Blood 2011, 118:1248-1254.

25. Douer D, Preston-Martin S, Chang E et al: High frequency of acute promyelocytic leukemia among Latinos with acute myeloid leukemia. Blood 1996, 87:308-313.

26. Estey $\mathrm{E}$, Thall $\mathrm{P}$, Kantarjian $\mathrm{H}$ et al: Association between increased body mass index and a diagnosis of acute promyelocytic leukemia in patients with acute myeloid leukemia. Leukemia 1997, 11:1661-1664.

27. Breen KA, Grimwade D, Hunt BJ: The pathogenesis and management of the coagulopathy of acute promyelocytic leukaemia. Br J Haematol 2012, 156:24-36.

An excellent review of the coagulopathy that dominates the initial presentation and early treatment of APL.

28. Daniel MT, Koken M, Romagne O et al: PML protein expression in hematopoietic and acute promyelocytic leukemia cells. Blood 1993, 82:1858-1867.

29. Falini B, Flenghi L, Fagioli M et al: Immunocytochemical diagnosis of acute promyelocytic leukemia (M3) with the monoclonal antibody PG-M3 (anti-PML). Blood 1997, 90:4046-4053.

30.

et al: Definition of relapse risk and role of nonanthracycline drugs for consolidation in patients with acute promyelocytic leukemia: a joint study of the PETHEMA and GIMEMA cooperative groups. Blood 2000, 96:1247-1253.

31. Frankel SR, Eardley A, Lauwers G et al: The "retinoic acid syndrome" in acute promyelocytic leukemia. Ann Intern Med 1992, 117:292-296. 
32. Fenaux P, Le Deley M, Castaigne $S$ et al: Effect of all transretinoic acid in newly diagnosed acute promyelocytic leukemia. Results of a multicenter randomized trial. European APL 91 Group. Blood 1993, 82:3241-3249.

33. Fenaux $\mathrm{P}$, Chastang $\mathrm{C}$, Chevret $\mathrm{S}$ et al: A randomized comparison of all transretinoic acid (ATRA) followed by chemotherapy and ATRA plus chemotherapy and the role of maintenance therapy in newly diagnosed acute promyelocytic leukemia. The European APL Group. Blood 1999, 94:1192-1200.

34. Head D, Kopecky K, Weick J et al: Effect of aggressive daunomycin therapy on survival in acute promyelocytic leukemia. Blood 1995, 86:17171728.

35. Avvisati G, Petti MC, Lo-Coco F et al: Induction therapy with idarubicin alone significantly influences event-free survival duration in patients with newly diagnosed hypergranular acute promyelocytic leukemia: final results of the GIMEMA randomized study LAP 0389 with 7 years of minimal follow-up. Blood 2002, 100:3141-3146.

36. Mandelli F, Diverio D, Avvisati G et al: Molecular remission in PML/RAR $\alpha$-positive acute promyelocytic leukemia by combined all-trans retinoic acid and idarubicin (AIDA) therapy. Blood 1997, 90:1014-1021.

37. , Rayón C et al: A modified AIDA protocol with anthracycline-based consolidation results in high antileukemic efficacy and reduced toxicity in newly diagnosed PML/RAR $\alpha$-positive acute promyelocytic leukemia. Blood 1999, 94:3015-3021.

38. Ades L, Chevret S, Raffoux E et al: Is cytarabine useful in the treatment of acute promyelocytic leukemia? Results of a randomized trial from the European Acute Promyelocytic Leukemia Group. J Clin Oncol 2006, 24:5703-5710.

39. - Lo-Coco F, Avvisati G, Vignetti M et al: Front-line treatment of acute promyelocytic leukemia with AIDA induction followed by risk-adapted consolidation for adults younger than 61 years: results of the AIDA-2000 trial of the GIMEMA Group. Blood 2010, 116:3171-3179.

An example of what can be achieved when APL is treated with (a) ATRA and anthracycline-based chemotherapy, and (b) intensified consolidation that includes intermediate-dose cytarabine. 
40. Sanz MA, Montesinos P, Rayon C et al: Risk-adapted treatment of acute promyelocytic leukemia based on all-trans retinoic acid and anthracycline with addition of cytarabine in consolidation therapy for high-risk patients: further improvements in treatment outcome. Blood 2010, 115:5137-5146.

41. Shen Z-X, Shi Z-Z, Fang J et al: All-trans retinoic acid/As2O3 combination yields a high quality remission and survival in newly diagnosed acute promyelocytic leukemia. Proc Natl Acad Sci U S A 2004, 101:5328-5335.

42. - Ravandi F, Estey E, Jones D et al: Effective treatment of acute promyelocytic leukemia with all-trans-retinoic acid, arsenic trioxide, and gemtuzumab ozogamicin. J Clin Oncol 2009, 27:504-510.

This study demonstrates that ATRA/ATO in induction and consolidation is adequate for low-risk patients, but high-risk patients had inferior outcomes despite gemtuzumab ozogamicin.

43. - Powell BL, Moser B, Stock W et al: Arsenic trioxide improves event-free and overall survival for adults with acute promyelocytic leukemia: North American Leukemia Intergroup Study C9710. Blood 2010, 116:3751-3757.

A randomized phase III study that clearly demonstrated the benefit of including ATO in post-remission therapy.

44. •• Iland HJ, Bradstock K, Supple SG et al: All-trans-retinoic acid, idarubicin, and IV arsenic trioxide as initial therapy in acute promyelocytic leukemia (APML4). Blood 2012, 120:1570-1580.

This study reports excellent interim analysis results with a regimen that incorporates the three most active agents currently available for the treatment of APL (ATRA, ATO and idarubicin). Exposure to idarubicin was limited to one cycle, and the white cell count at diagnosis was not associated with a significant increase in early deaths or relapses.

45. - Lo-Coco F, Avvisati G, Orlando SM et al: ATRA and asenic trioxide (ATO) versus ATRA and idarubicin (AIDA) for newly diagnosed, non high-risk acute promyelocytic leukemia (APL): Results of the phase III, prospective, randomized, Intergroup APL0406 Study by the Italian-German Cooperative Groups GIMEMA-SAL-AMLSG. In: 54th American Society of Hematology Annual Meeting. Atlanta, GA; 2012.

This is an important report, currently available only in abstract form. It demonstrates in a randomized, phase III study that ATRA/ATO is non-inferior, and probably superior, to an ATRA/chemotherapy strategy. 
46. Au WY: A biography of arsenic and medicine in Hong Kong and China. Hong Kong Med 2011, 17:507-513.

47. Zhang $\mathrm{T}$, Sun $\mathrm{H}, \mathrm{Hu} \mathrm{H}$ : Treatment of acute promyelocytic leukemia with Ailing number one combination therapy: a study of 73 cases [in Chinese]. Heilongjiang Journal of Traditional Chinese Medicine 1981, 4:40-44.

48. Sun H, Ma L, Hu X, Zhang T: Ai-Lin I treated 32 cases of acute promyelocytic leukemia. Chin J Integrat Chin West Med 1992, 12:170-171.

49. Chen GQ, Shi XG, Tang W et al: Use of arsenic trioxide (As2O3) in the treatment of acute promyelocytic leukemia (APL): I. As2O3 exerts dosedependent dual effects on APL cells. Blood 1997, 89:3345-3353.

50. Zheng X, Seshire A, Ruster B et al: Arsenic but not all-trans retinoic acid overcomes the aberrant stem cell capacity of PML/RARalpha-positive leukemic stem cells. Haematologica 2007, 92:323-331.

51. Nasr R, Guillemin M-C, Ferhi O et al: Eradication of acute promyelocytic leukemia-initiating cells through PML-RARA degradation. Nat Med 2008, 14:1333-1342.

52. Forkner C, Scott T: Arsenic as a therapeutic agent in chronic myelogenous leukemia: Preliminary report. JAMA 1931, 97:3-5.

53. Shen ZX, Chen GQ, Ni JH et al: Use of arsenic trioxide (As2O3) in the treatment of acute promyelocytic leukemia (APL): II. Clinical efficacy and pharmacokinetics in relapsed patients. Blood 1997, 89:3354-3360.

54. Soignet SL, Maslak P, Wang ZG et al: Complete remission after treatment of acute promyelocytic leukemia with arsenic trioxide. N Engl J Med 1998, 339:1341-1348.

55. Soignet SL, Frankel SR, Douer D et al: United States multicenter study of arsenic trioxide in relapsed acute promyelocytic leukemia. J Clin Oncol 2001, 19:3852-3860.

56. Niu C, Yan H, Yu T et al: Studies on treatment of acute promyelocytic leukemia with arsenic trioxide: remission induction, follow-up, and molecular monitoring in 11 newly diagnosed and 47 relapsed acute promyelocytic leukemia patients. Blood 1999, 94:3315-3324.

57. Spencer A, Firkin F: Arsenic trioxide treatment of relapsed acute promyelocytic leukaemia: initial Australian experience. Aust N Z J Med 1999, 29:385-386. 
58. Kwong YL, Au WY, Chim CS et al: Arsenic trioxide- and idarubicin-induced remissions in relapsed acute promyelocytic leukaemia: clinicopathological and molecular features of a pilot study. Am J Hematol 2001, 66:274-279.

59. Au WY, Lie AKW, Chim CS et al: Arsenic trioxide in comparison with chemotherapy and bone marrow transplantation for the treatment of relapsed acute promyelocytic leukaemia. Ann Oncol 2003, 14:752-757.

60. Leoni F, Gianfaldoni G, Annunziata M et al: Arsenic trioxide therapy for relapsed acute promyelocytic leukemia: a bridge to transplantation. Haematologica 2002, 87:485-489.

61. Raffoux E, Rousselot P, Poupon J et al: Combined treatment with arsenic trioxide and all-trans-retinoic acid in patients with relapsed acute promyelocytic leukemia. J Clin Oncol 2003, 21:2326-2334.

62. Shigeno K, Naito K, Sahara N et al: Arsenic trioxide therapy in relapsed or refractory Japanese patients with acute promyelocytic leukemia: updated outcomes of the phase II study and postremission therapies. Int J Hematol 2005, 82:224-229.

63. Lazo G, Kantarjian H, Estey E et al: Use of arsenic trioxide (As2O3) in the treatment of patients with acute promyelocytic leukemia: the M. D. Anderson experience. Cancer 2003, 97:2218-2224.

64. Aribi A, Kantarjian HM, Estey EH et al: Combination therapy with arsenic trioxide, all-trans retinoic acid, and gemtuzumab ozogamicin in recurrent acute promyelocytic leukemia. Cancer 2007, 109:1355-1359.

65. Carmosino I, Latagliata R, Avvisati G et al: Arsenic trioxide in the treatment of advanced acute promyelocytic leukemia. Haematologica 2004, 89:615-617.

66. Thomas X, Pigneux A, Raffoux E et al: Superiority of an arsenic trioxide-based regimen over a historic control combining all-trans retinoic acid plus intensive chemotherapy in the treatment of relapsed acute promyelocytic leukemia. Haematologica 2006, 91:996-997.

67. Shen Y, Shen ZX, Yan H et al: Studies on the clinical efficacy and pharmacokinetics of low-dose arsenic trioxide in the treatment of relapsed acute promyelocytic leukemia: a comparison with conventional dosage. Leukemia 2001, 15:735-741. 
68. Thirugnanam R, George B, Chendamarai E et al: Comparison of clinical outcomes of patients with relapsed acute promyelocytic leukemia induced with arsenic trioxide and consolidated with either an autologous stem cell transplant or an arsenic trioxide-based regimen. Biol Blood Marrow Transplant 2009, 15:1479-1484.

This paper addresses the issue of how to consolidate patients following achievement of a second CR after ATO-based therapy. Patients treated with further ATO/ATRA had a better EFS than patients who subsequently underwent autologous stem cell transplantation.

69. Sanz MA, Grimwade D, Tallman MS et al: Management of acute promyelocytic leukemia: recommendations from an expert panel on behalf of the European LeukemiaNet. Blood 2009, 113:1875-1891.

70. Hu J, Liu Y-F, Wu C-F et al: Long-term efficacy and safety of all-trans retinoic acid/arsenic trioxide-based therapy in newly diagnosed acute promyelocytic leukemia. Proc Natl Acad Sci U S A 2009, 106:3342-3347.

71. Dai C-W, Zhang G-S, Shen J-K et al: Use of all-trans retinoic acid in combination with arsenic trioxide for remission induction in patients with newly diagnosed acute promyelocytic leukemia and for consolidation/maintenance in CR patients. Acta Haematol 2009, 121:1-8.

72. Estey E, Garcia-Manero G, Ferrajoli A et al: Use of all-trans retinoic acid plus arsenic trioxide as an alternative to chemotherapy in untreated acute promyelocytic leukemia. Blood 2006, 107:3469-3473.

73. Mathews V, George B, Lakshmi KM et al: Single-agent arsenic trioxide in the treatment of newly diagnosed acute promyelocytic leukemia: durable remissions with minimal toxicity. Blood 2006, 107:2627-2632.

74. Ghavamzadeh A, Alimoghaddam K, Ghaffari SH et al: Treatment of acute promyelocytic leukemia with arsenic trioxide without ATRA and/or chemotherapy. Ann Oncol 2006, 17:131-134.

75. - Ghavamzadeh A, Alimoghaddam K, Rostami S et al: Phase Il study of single-agent arsenic trioxide for the front-line therapy of acute promyelocytic leukemia. J Clin Oncol 2011, 29:2753-2757.

Together with [76•], these data show the results of treatment with single agent ATO during induction and consolidation.

76. Mathews V, George B, Chendamarai E et al: Single-agent arsenic trioxide in the treatment of newly diagnosed acute promyelocytic leukemia: long-term follow-up data. J Clin Oncol 2010, 28:3866-3871. 
Together with [75•], these data show the results of treatment with single agent ATO during induction and consolidation.

77. Gore SD, Gojo I, Sekeres MA et al: Single cycle of arsenic trioxide-based consolidation chemotherapy spares anthracycline exposure in the primary management of acute promyelocytic leukemia. J Clin Oncol 2010, 28:1047-1053.

78. Iland HJ, Bradstock K, Seymour J et al: Results of the APML3 trial incorporating all-trans-retinoic acid and idarubicin in both induction and consolidation as initial therapy for patients with acute promyelocytic leukemia. Haematologica 2012, 97:227-234.

79. Au W-Y, Kwong Y-L: Arsenic trioxide: safety issues and their management. Chung Kuo Yao Li Hsueh Pao 2008, 29:296-304.

80. Firkin F: Oral administration of arsenic trioxide in the treatment of acute promyelocytic leukaemia and accelerated phase chronic myeloid leukaemia: an Australian single-centre study. Intern Med J 2012, 42:948-952.

81. Kumana CR, Au WY, Lee NSL et al: Systemic availability of arsenic from oral arsenic-trioxide used to treat patients with hematological malignancies. Eur J Clin Pharmacol 2002, 58:521-526.

82. Siu C-W, Au W-Y, Yung C et al: Effects of oral arsenic trioxide therapy on QT intervals in patients with acute promyelocytic leukemia: implications for long-term cardiac safety. Blood 2006, 108:103-106.

83. Au W-Y, Kumana CR, Lee HKK et al: Oral arsenic trioxide-based maintenance regimens for first complete remission of acute promyelocytic leukemia: a 10-year follow-up study. Blood 2011, 118:6535-6543.

Shows oral ATO used primarily for prolonged maintenance of first CR is safe and beneficial.

84. Au WY, Li C-K, Lee V et al: Oral arsenic trioxide for relapsed acute promyelocytic leukemia in pediatric patients. Pediatr Blood Cancer 2012, 58:630-632.

85. Lu D-P, Qiu J-Y, Jiang B et al: Tetra-arsenic tetra-sulfide for the treatment of acute promyelocytic leukemia: a pilot report. Blood 2002, 99:3136-3143.

86. - Zhu Z-H, Wu D-P, Jin J et al: Oral realgar-indigo naturalis formula achieved comparably high rate of remission and survival to intravenous arsenic trioxide as a front-line treatment in newly diagnosed acute promyelocytic leukemia: A multi-center randomized trial APL07. In: 54th American Society of Hematology Annual Meeting. Atlanta, GA; 2012. 
This report, currently available only in abstract form, provides data that an oral arsenic formulation (realgar-indigo naturalis) is as effective as IV ATO when combined with ATRA during induction and maintenance.

87. Chen H, MacDonald RC, Li S et al: Lipid encapsulation of arsenic trioxide attenuates cytotoxicity and allows for controlled anticancer drug release. J Am Chem Soc 2006, 128:13348-13349.

88. Diaz Z, Mann KK, Marcoux S et al: A novel arsenical has antitumor activity toward As2O3-resistant and MRP1/ABCC1-overexpressing cell lines. Leukemia 2008, 22:1853-1863.

89. Konig A, Wrazel L, Warrell RP, Jr. et al: Comparative activity of melarsoprol and arsenic trioxide in chronic B-cell leukemia lines. Blood 1997, 90:562-570.

90. Au W-Y, Tam S, Fong BM, Kwong Y-L: Determinants of cerebrospinal fluid arsenic concentration in patients with acute promyelocytic leukemia on oral arsenic trioxide therapy. Blood 2008, 112:3587-3590.

91. Au W-Y, Hon C, Yau K et al: Two cases of monocular visual loss during oral arsenic trioxide therapy of acute promyelocytic leukemia. Am J Hematol 2009, 84:699. 
Figure 1: Freedom from relapse, stratified by Sanz risk category, in the ALLG APML4 study [44].

This research was originally published in Blood. Iland HJ et al: All-trans-retinoic acid, idarubicin, and IV arsenic trioxide as initial therapy in acute promyelocytic leukemia (APML4). Blood 2012, 120(8):1570-1580. (C) the American Society of Hematology. 
Table 1: Studies utilizing ATO as part of initial therapy during induction and/or post-remission

\begin{tabular}{|c|c|c|c|c|c|c|c|c|c|c|c|c|}
\hline \multirow[t]{2}{*}{ Reference } & \multirow[t]{2}{*}{$\begin{array}{l}\text { Risk group } \\
\text { restriction }\end{array}$} & \multirow[t]{2}{*}{$\begin{array}{c}\text { No. of } \\
\text { patients }\end{array}$} & \multicolumn{4}{|c|}{ Induction } & \multicolumn{4}{|c|}{ Post-remission } & \multicolumn{2}{|c|}{ Outcomes } \\
\hline & & & ATRA & ATO & $\begin{array}{l}\text { Chemotherapy } \\
\text { (all risk groups) }\end{array}$ & 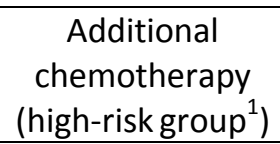 & ATRA & ATO & $\begin{array}{l}\text { Consolidation } \\
\text { chemotherapy }\end{array}$ & 6MP/MTX ${ }^{2}$ & OS & DFS \\
\hline $\begin{array}{c}\text { Matthews } \\
{[76]}\end{array}$ & & 72 & & $x$ & & $\mathrm{x}$ & & $x$ & & & $\begin{array}{c}74 \% \\
(5 \mathrm{yr})\end{array}$ & $\begin{array}{l}80 \% \\
(5 \mathrm{yr})\end{array}$ \\
\hline $\begin{array}{c}\text { Ghavamzadeh } \\
\text { [75] }\end{array}$ & & 197 & & $x$ & & $x$ & & $x$ & & & $\begin{array}{c}64 \% \\
(5 \mathrm{yr}) \\
\end{array}$ & $\begin{array}{l}67 \% \\
(5 \mathrm{yr}) \\
\end{array}$ \\
\hline $\begin{array}{c}\text { Powell }^{3} \\
\text { [43] }\end{array}$ & & 244 & $x$ & & $x$ & $x$ & $x$ & $x$ & $x$ & $x^{3}$ & $\begin{array}{l}86 \% \\
(3 \mathrm{yr})\end{array}$ & $\begin{array}{c}90 \% \\
(3 \mathrm{yr})\end{array}$ \\
\hline $\begin{array}{l}\text { Gore } \\
\text { [77] }\end{array}$ & & 45 & $x$ & & $x$ & $x$ & $x$ & $x$ & $x$ & $x^{4}$ & $\begin{array}{l}88 \% \\
(3 \mathrm{yr})\end{array}$ & $\begin{array}{l}89 \% \\
(3 \mathrm{yr})\end{array}$ \\
\hline $\begin{array}{c}\mathrm{Hu} \\
{[70]}\end{array}$ & & 85 & $x$ & $x$ & & $x$ & $x$ & $x$ & $x$ & $x^{5}$ & $\begin{array}{c}92 \% \\
(5 \mathrm{yr}) \\
\end{array}$ & $\begin{array}{l}95 \% \\
(5 \mathrm{yr}) \\
\end{array}$ \\
\hline $\begin{array}{l}\text { Dai } \\
{[71]}\end{array}$ & & 90 & $x$ & $x$ & & $x$ & $x$ & $x$ & $x$ & & - & $\begin{array}{c}93 \% \\
(3 \mathrm{yr})\end{array}$ \\
\hline $\begin{array}{c}\text { Ravandi } \\
\text { [42] }\end{array}$ & & 82 & $x$ & $x$ & & $x$ & $x$ & $x$ & & & $\begin{array}{c}85 \% \\
(3 \mathrm{yr})\end{array}$ & $\begin{array}{l}81 \% \\
(3 \mathrm{yr})\end{array}$ \\
\hline $\begin{array}{c}\text { lland } \\
\text { [44] }\end{array}$ & & 124 & $x$ & $x$ & $x$ & & $x$ & $x$ & & $x$ & $\begin{array}{c}93 \% \\
(2 \mathrm{yr})\end{array}$ & $\begin{array}{l}98 \% \\
(2 \mathrm{yr})\end{array}$ \\
\hline $\begin{array}{c}{\text { Lo } \mathrm{Coco}^{6}} \\
{[45]}\end{array}$ & $\begin{array}{l}\text { High risk } \\
\text { excluded }^{6}\end{array}$ & 79 & $x$ & $x$ & & & $x$ & $x$ & & & $\begin{array}{c}99 \% \\
(2 \mathrm{yr})\end{array}$ & $\begin{array}{c}97 \% \\
(2 \mathrm{yr})\end{array}$ \\
\hline
\end{tabular}

${ }^{1}$ Definition of high risk varied, and included: (a) elevated white cell count at presentation (variable thresholds); (b) white cell count rising above pre-specified levels during induction (variable thresholds); (c) development of differentiation syndrome

${ }^{2}$ 6MP/MTX: maintenance included 6-mercaptopurine plus methotrexate

${ }^{3}$ Results shown are for patients randomized to ATO in consolidation; $50 \%$ of patients were also randomized to $6 \mathrm{MP} / \mathrm{MTX}$ maintenance

${ }^{4}$ Only high-risk patients received $6 \mathrm{MP} / \mathrm{MTX}$ maintenance

${ }^{5}$ In addition to ATRA/ATO, maintenance included 6MP or MTX 
${ }^{6}$ Results shown are for patients randomized to ATRA/ATO induction; only patients with initial white cell count $\leq 10 \times 10^{9} / \mathrm{L}$ were included 

Table 2: Toxicity associated with therapeutic ATO

\begin{tabular}{|c|c|}
\hline Differentiation syndrome & - generally less severe than following ATRA \\
\hline Liver & - hepatitis (especially ALT and AST elevation) \\
\hline Cardiac & $\begin{array}{l}\text { - QTc prolongation (aggravated by hypokalemia and } \\
\text { hypomagnesemia, and other drugs that prolong the QTC } \\
\text { interval) } \\
\text { - ventricular arrhythmias and torsades de pointes }\end{array}$ \\
\hline Gastrointestinal & $\begin{array}{l}\text { - } \text { nausea and vomiting } \\
\text { - diarrhea } \\
\text { - } \text { mucositis } \\
\text { - } \text { enterocolitis } \\
\end{array}$ \\
\hline Skin & $\begin{array}{l}\text { - } \text { hyperpigmentation } \\
\text { - } \text { rash } \\
\text { - reactivation of H. zoster and H. simplex }\end{array}$ \\
\hline Bone marrow & - myelosuppression, especially neutropenia \\
\hline Neurologic & $\begin{array}{l}\text { - } \text { peripheral neuropathy (predominantly sensory) } \\
\text { - CNS (infrequent, although systemically administered ATO is } \\
\text { found in cerebrospinal fluid [90] and the eye [91]) }\end{array}$ \\
\hline Biochemical & $\begin{array}{l}\text { - } \text { hyperglycemia } \\
\text { - hypoalbuminemia } \\
\text { - hypokalemia } \\
\text { - hypophosphatemia } \\
\text { - } \text { renal failure }\end{array}$ \\
\hline
\end{tabular}




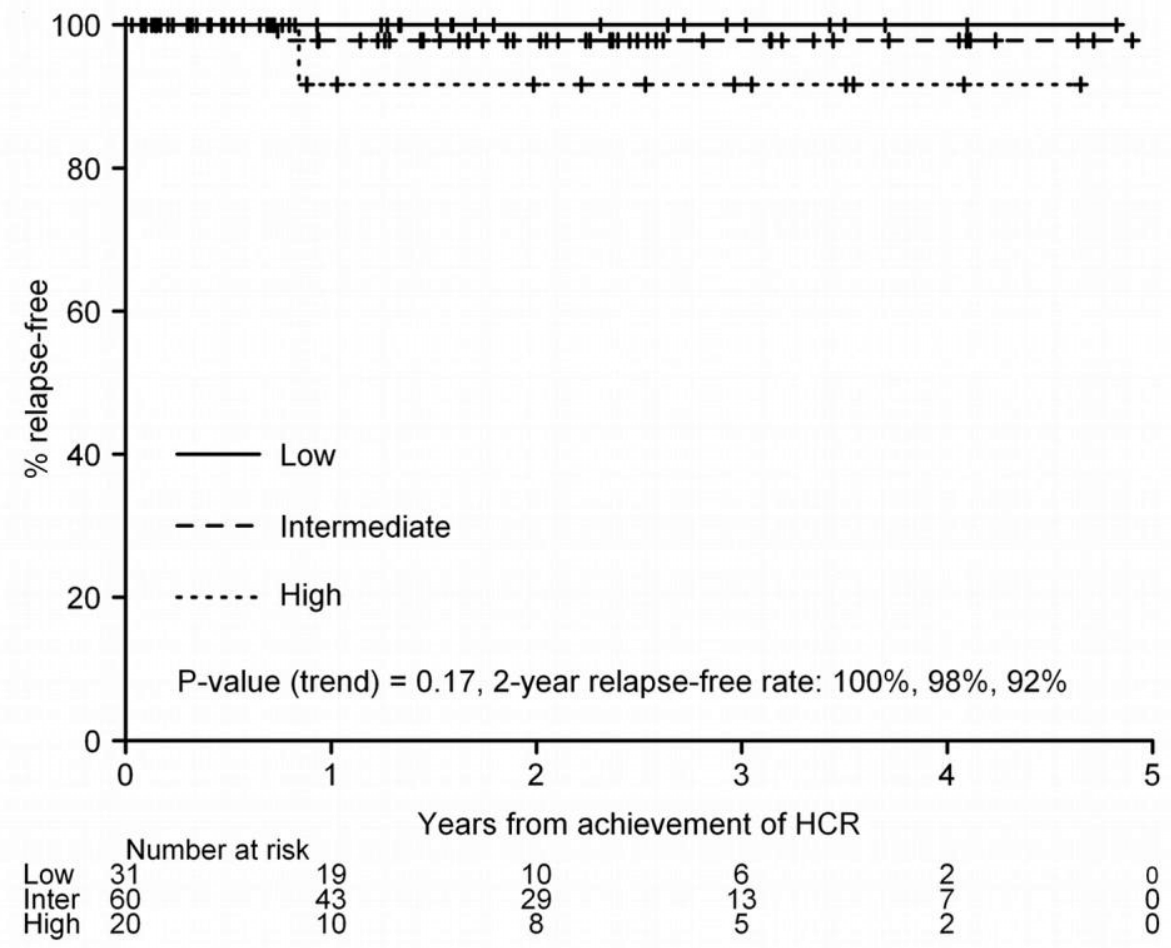

